\title{
Impact of buffalo's milk on rat kidney exposed to noise
}

\author{
Zohre Jafarzadeh $^{1}{ }^{\circledR}$ Jamshid Alizadeh $^{1}$, Massumeh Ahmadizadeh ${ }^{12^{*}}{ }^{\circledR}$, Kambiz Angali $^{3}$ \\ ${ }^{1}$ Department of Occupational Health Engineering, School of Health, Ahvaz Jundishapur University of Medical Sciences, Ahvaz, Iran \\ ${ }^{2}$ Physiology Research Center, Ahvaz Jundishapur University of Medical Sciences, Ahvaz, Iran \\ ${ }^{3}$ Department of Statistics and Epidemiology, School of Health, Ahvaz Jundishapur University of Medical Sciences, Ahvaz, Iran
}

\section{A R T I C L E I N F O}

Article Type:

Original

\section{Article History:}

Received: 20 October 2017

Accepted: 5 January 2018

Published online: 10 February 2018

\section{Keywords:}

Buffalo's milk

Noise

Glutathione

Malondialdehyde

Nephrotoxicity

\begin{abstract}
A B S T R A C T
Introduction: Noise is defined as unpleasant and unwanted sound. Noise exposure has been associated with numerous health effects in human and experimental animals. Milk has very high nutritional value. It has been reported that this compound has protective properties against some chemical-induced toxicity.

Objectives: The purpose of this study was to determine the protecting impact of buffalo's milk on noise produced nephrotoxicity in rats.

Materials and Methods: Twenty adult Wistar male rats were divided into 4 groups in random order $(n=5)$. First group was used as control, second group have received buffalo milk (1 $\mathrm{mL} / \mathrm{d}$ ) for 2 weeks, third group exposed to noise for about 100 decibels (dB) (2 weeks and 4 hours daily), fourth group received buffalo's milk (BM) $(1 \mathrm{~mL} / \mathrm{d}) 10$ minutes before exposed to noise (100 dB for 4 hours daily) for 14 consecutive days. Around 24 hours later, all rats were killed because of overdose of sodium pentobarbital. Blood samples were collected and processed for evaluation of blood urea nitrogen (BUN) and creatinine (Cr). We removed kidney tissues, one part of the kidney tissue processed for determination of malondialdehyde (MDA) and glutathione (GSH) concentrations. Other parts were excised for histopathological observations.

Results: The levels of BUN, Cr and MDA significantly increased, but the level of GSH markedly dropped in rats that exposed to noise in contrast to unexposed (control) animals. Histopathological alterations were also noted in rat kidney exposed to noise. Administration of BM did not change biochemical parameters when compared to those in control values. However, giving BM prior exposure rats to noise markedly decreased the levels of BUN, Cr and MDA and increased the level of GSH when compared to those in non-pretreated noise exposed rats. BM also restored noise-induced morphological changes in rat kidney.

Conclusion: This study demonstrated that exposed rats to noise-mediated kidney damage. BM showed a nephroprotective effect on noise caused oxidative stress and kidney dysfunction in rats.
\end{abstract}

\section{Implication for health policy/practice/research/medical education:}

Current study presented noise-induced elevation of malondialdehyde as an indication of lipid peroxidation and reduction of glutathione, elevation of BUN and Cr levels, as well as histopathological damage in rat kidney. These findings support that oxidative stress in the kidney is measured as an important part in kidney function. Bufallo's milk efficiently diminishes noise produced oxidative stress in the rat kidney. This observation supports the view that buffalo's milk has potential to protect kidney against noise-induced renal injury.

Please cite this paper as: Jafarzadeh Z, Alizadeh A, Ahmadizadeh M, Angali K. Impact of buffalo's milk on rat kidney exposed to noise. J Renal Inj Prev. 2018;7(4):230-234. Doi: 10.15171/jrip.2018.53.

\section{Introduction}

Noise is the main source of environmental frustration resulting in different adverse impacts in humans and animals. Noise is determined as an undesirable sound that is linked to different kind of health problems such as hearing damage, cardiovascular illness, increasing blood pressure, mental diseases, sleep disturbance and gastrointestinal motility disorder (1-7).

Histopathological injury in various tissues including brain, heart, spleen and liver were observed in female 
rats exposed to high-frequency stable noise (2). Recently, Zaghloul reported exposure rat to noise increased kidney weight and produced histopathological damage as well as highly significant decreased in the urine output (7).

The mechanism by which noise stress induced adverse effects in various organs is not completely understood. However, Pinar et al found the oxidant/antioxidant imbalance in erythrocytes of workers, who worked in a noisy environment (8). Said et al demonstrated noise stress reduced the activity of superoxide dismutase and increased malondialdehyde (MDA) levels in rats (3). Increasing evidence indicated that nutrition plays an essential role in the control of chronic diseases $(9,10)$. Food is not only vital for living but also inducing certain physiological functions and providing to the reduction of risk factors for adverse effects of xenobiotics $(10,11)$. Yu et al found that diet with low iron escalates exposure to noise-mediated hearing loss in rats (11).

Milk is well-known to be one of the main sources of nutrient that contains various substances recognized to be vital for human nutrition.It is an important source of protein, calcium, vitamin $\mathrm{A}$, vitamin $\mathrm{C}$, magnesium, and zinc (12-16). The beneficial effects of milk in prevention of adverse effect of xenobiotics were reported by several studies $(10,16,17)$. Water buffalo's milk is the main source of drinking milk in many countries. It is a good source of high levels of vitamin A, iron, and copper content, phosphorous contents, magnesium and other trace elements and it has an antioxidant capacity (12-15). To our knowledge, the effect of milk on noise produced nephrotoxicity has not been reported.

\section{Objectives}

The aim of the present study was to determine the impact of buffalo's milk on noise induced kidney injury in rats.

\section{Materials and Methods}

Adult male albino Wistar rats (200-250 g body weight) were provided from maintenance center of laboratory animals of Ahvaz Jundishapur University of Medical Sciences. The rats were kept under 12/12-hour darkness/ brightness conditions at a temperature of $23 \pm 2^{\circ} \mathrm{C}$ and they had free access to food and water. They were divided randomly into four groups (each 5), as follows:

Group I; control group (without exposed to noise and without administration buffalo's milk). The animals have been kept in the chamber with the same specification as that of the experimental groups except for the noise exposure.

Group II; received buffalo's milk $(1 \mathrm{~mL} / \mathrm{d})$ for 2 weeks without expose to noise.

Group III; exposed to noise (100 decibels [dB], 4 hours daily) for 2 weeks with administration $1 \mathrm{~mL} / \mathrm{d}$ distilled water 10 minutes before exposing.

Group IV; exposed to noise $(100 \mathrm{~dB}, 4$ hours daily for 2 weeks) with administration $1 \mathrm{~mL} / \mathrm{d}$ buffalo's milk 10 minutes before exposing. All animals were killed 24 hours after the last experiment, with an overdose of sodium pentobarbital.

Blood samples were used for evaluation blood urea nitrogen (BUN) and creatinine (Cr). The methods of diacetyl monoxime and Jaffe were used for the evaluation of BUN and Cr, respectively $(18,19)$.

One part of the kidney tissues was used for evaluation of MDA and glutathione (GSH) levels. MDA level was determined by the method of Buege and Aust (20), and GSH level was measured with (5,5'-dithio-bis-[2nitrobenzoic acid]) by Ellman's method (21). Another part of the kidney tissues was processed for light microscopy. Five histopathological sections, each at least $15 \mu \mathrm{m}$ apart were taken from each tissue block and stained with hematoxylin and eosin (H\&E).

\section{Noise exposure}

From a large textile factory, the intended noise $(100 \mathrm{db}$, $700-5700 \mathrm{~Hz}$ ) was recorded and reproduced in a soundinsulated animal room. During noise exposure, The intensity was measured regularly at inside the animal room using calibrated Brüel and Kjær noise meter device (MODEL 2238). Selected sound intensity was based on previous studies (22-24).

\section{Source of buffalo's milk}

Milk was collected early morning from buffalo's farm. The milk samples immediately were boiled for pasteurization and after cooling, samples were kept in the refrigerator.

\section{Ethical issues}

The research followed the tenets of the Declaration of Helsinki. This project was approved by Ethics Committee of Ahvaz Jundishapur University of Medical Sciences. Prior to the experiment, the protocols were confirmed to be in accordance with the guidelines of Animal Ethics Committee of Ahvaz Jundishapur University of Medical Sciences.

\section{Data analysis}

Data of blood biochemistry and kidney were tested for homogeneity of variance and once homogeneity was confirmed, analysis of variance (ANOVA) was performed and Welch's t-test was used otherwise. For the comparison of means to determine significant differences $(P \leq 0.05)$, the Tukey's test was used. In this study, five animals were assigned randomly to each group. SPSS 23 software was applied to analyze the data.

\section{Results}

Exposure of rats to noise showed a significant increase in serum BUN level compared to the unexposed control group $(P \leq 0.05)$. Buffalo's milk (BM) had no impact on serum BUN level when compared to the control group. However, giving BM prior exposure animals to noise significantly decreased BUN level compared to those in nontreated rats exposed to noise (Figure 1A). Similarly, the 
level of $\mathrm{Cr}$ in rats exposed to noise increased significantly when compared to control value. BM had no effects on $\mathrm{Cr}$, but significantly decreased $\mathrm{Cr}$ level in exposed rats when compared to non-pretreatment rats exposed to noise (Figure 1B).

Kidney GSH concentration diminished significantly $(P \leq 0.05)$ in the noise exposure group compared to the unexposed control rats. Buffalo's milk had no impact on rat kidney GSH level when compared to the control group. The buffalo's milk significantly $(P \leq 0.05)$ increased the GSH level in noise exposure rats in comparison with the those in noise group (Figure 1C).

Exposure to noise increased MDA concentration in rat kidney when compared to the control group $(P \leq 0.05)$. Buffalo's milk had no impact on MDA level in rat kidney when compared to the control group. In the kidney tissue, MDA level decreased significantly $(P \leq 0.05)$ in noise group by administration of buffalo's milk when comparing to non-pretreated rats exposed to noise (Figure 1D).

In control, there was no detectable injury in rat kidney (Figure 2). However, compared with the control rats, histopathological alterations included dilatation, congestion area and sign of disorganization were seen in rat kidney exposed to noise. Light microscopy revealed that renal tubular cells were swollen, had loss of staining capacity, and nuclei appeared to be dilated (Figure 3). Buffalo's milk had no effect on kidney cells. However, it protected kidney against noise-induced injury (Figure 4).

\section{Discussion}

Our data showed that noise exposure caused elevation of BUN and $\mathrm{Cr}$ when compared to those in unexposed control male rats. Helal et al found the exposure of female rats to noise significantly increased Cr. They also reported that exposure of rats to noise induced histopathological damage in the kidney (25). Zaghloul found renal histopathological alterations as well as reduction in urine output in rats exposed to noise (7). Thus, our findings along with other studies, support the view that noise exposure induced adverse effects on kidney. Harmful effects of noise on an extra-auditory system including endocrine, cardiovascular and neurologic functions have been reported (5-8).

The mechanism by which noise induced adverse effects has not been completely understood. However, the production of reactive oxygen species (ROS) has been known to be part of the fundamental mechanism for noise-mediated hearing loss.Our data showed MDA is an index of lipid peroxidation increased following exposure to noise. Liu et al reported that noise mediated oxidative stress and caused cognitive decline in mice (26). Dereköy et al found, exposure of rabbit to noise produced oxidative stress and causing hearing loss (27). Koc et al reported that rosuvastatin decreased oxidative stress caused by noise exposure in rat serum (28). We observed in contrast to MDA, the level of GSH decreased in rats following exposure to noise. GSH has an antioxidant capacity and prevents cells against reactive toxic metabolites and electrophilic chemicals. We observed exposure rats to noise for 2 weeks significantly diminished GSH level when compared to unexposed rats. Ohinata et al reported that GSH supplement protected noise-induced hearing loss in guinea pigs (29). The impact of noise-induced oxidative stress in kidney has not been reported previously.
(A) 25

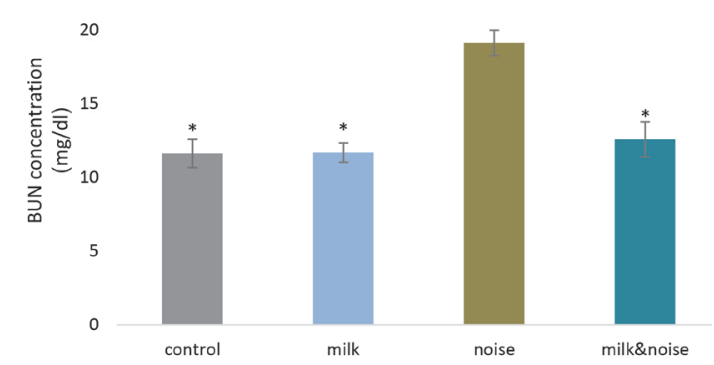

(C)

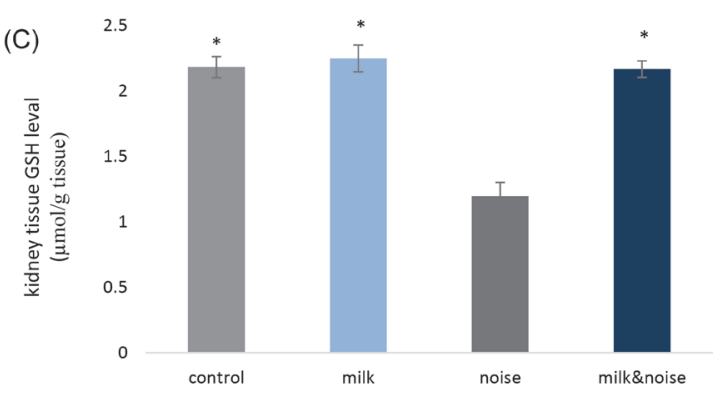

(B)
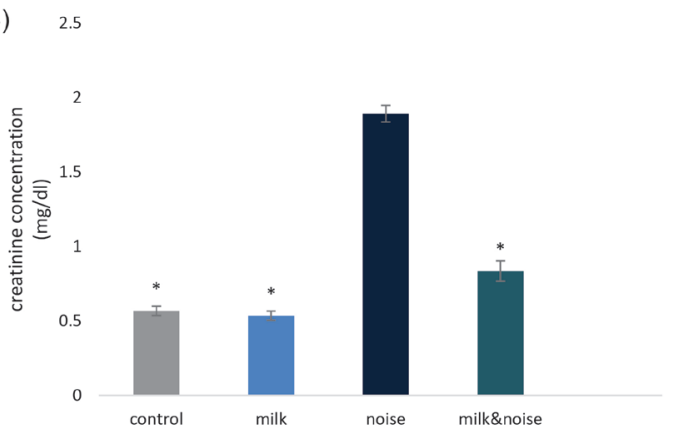

(D)

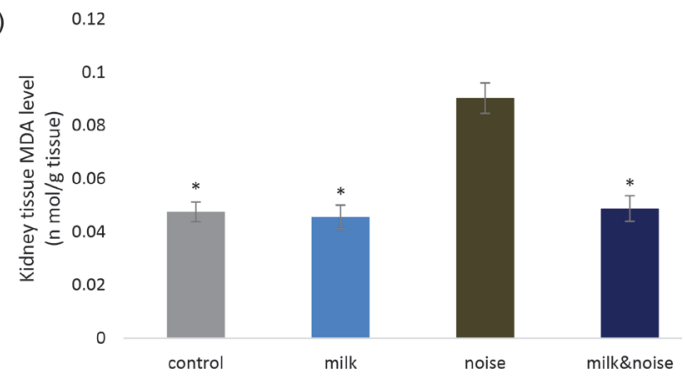

Figure 1. Effects of buffalo's milk on (A) BUN, (B) $\mathrm{Cr}$, (C) GSH and (D) MDA levels in rats exposed to noise. *Significantly different from rats exposed to noise $(P \leq 0.05)$. 


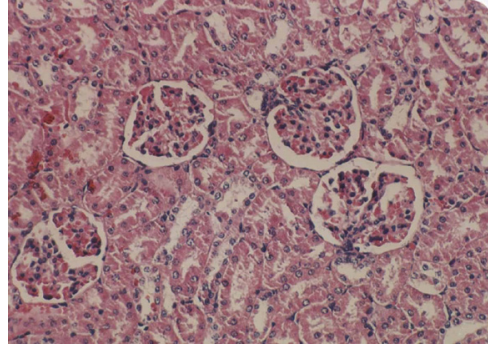

Figure 2. The control rat kidney. Showed cells are intact and no obvious injury were seen $(H \& E)(\times 200)$.

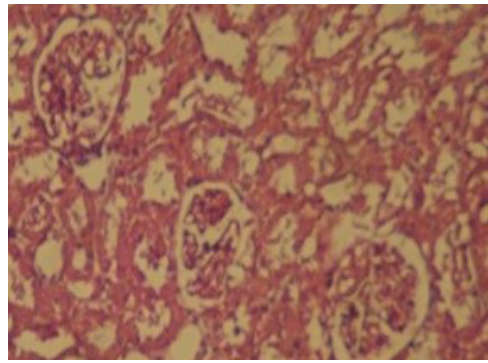

Figure 3. The noise exposed rat kidney. Showed dilatation renal tubular cells had loss of staining capacity and presence of many vacuoles in renal tubular cells $(H \& E)(\times 200)$.

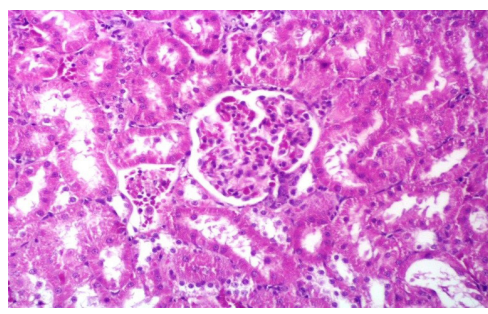

Figure 4. Light micrograph of rat kidney giving buffalo's milk and exposed to noise. Showed cells are intact and no obvious injury were seen $(H \& E)(\times 200)$

However, the results of the present study support the view that similar to other tissues, generation of oxidative stress at least in part is in charge for its noxious effects on rat kidney.

The role of nutrition in preventing cells against reactive chemical species and toxic environmental chemical has been generated considerable interest. Loukzadeh et al showed that vitamin $\mathrm{C}$ diminished noise-induced hearing loss in rats (30). Wang et al found that orientin has potential to protect mice against noise-induced cognitive impairments (31).

The beneficial effects of milk in prevention of some xenobiotics induced nephrotoxicity were reported by several authors $(16,17)$. Al-Hashem reported that camel's milk prevents rat's kidney against aluminum produced nephrotoxicity. He suggested that the protecting impact of camel's milk could be related to its antioxidant capacity (32). The antioxidant property and protective effect of buffalo's milk on toluene induced nephrotoxicity were also reported (33).

Our data showed that pretreatment of rats with buffalo's milk before to noise exposure diminished noise induced renal injury. High level of vitamin A and vitamin C are reported in considerable amounts within buffalo's milk (15). These chemical agents act as antioxidant and have been founded to prevent tissues against chemical produced toxicity. Zinc and other certain minerals in this milk can also act as antioxidants (15). Our data along with others further support the view that the preventing effects of buffalo's milk against chemical produced oxidative stress could be due to its antioxidant property. Dereköy et al showed treatment of rabbits with vitamin $C$ caused protection against the harmful effect of noise and hearing loss (27). In the view of the present study, we found that the importance of milk in protecting the kidney against noise induced oxidative stress and produced nephrotoxicity.

\section{Conclusion}

Noise has an unwilling impact on rat kidney. Our data revealed that rats exposed to noise impaired renal function as well as induced oxidative stress. Buffalo's milk administrated before exposure to noise minimized noiseinduced nephrotoxicity. Therefore, drinking milk could be beneficial for reducing adverse effects of noise. Further studies are needed to confirm this protective.

\section{Acknowledgments}

The authors wish to thank the research deputy of Ahvaz Jundishapur University of Medical Sciences for offering the grants for this investigation. The source of data used in this paper was from master thesis of Zohre Jafarzadeh, student of Occupational Health Engineering Department, School of Health, Ahvaz Jundishapur University of Medical Sciences, Ahvaz, Iran. Our special thanks go to Dr. S.S. Malaekh for reviewing histopathological samples

\section{Conflicts of interest}

The authors declared no competing interests.

\section{Authors' contribution}

ZJ and JA provided technical assistance, collection and preparation of the manuscript. KA analyzed the data. MA designed, supervised the study and prepared the final draft of the article.

\section{Ethical considerations}

Ethical issues (including plagiarism, data fabrication, double publication) have been completely observed by the authors.

\section{Funding/Support}

This study was supported by Physiology Research Center and the research deputy of Ahvaz Jundishapur University of Medical Sciences (Grant \#APRC-94-24). 


\section{References}

1. Sriopas A, Chapman R, Sutammasa S, Siriwong W. Occupational noise-induced hearing loss in auto part factory workers in welding units in Thailand. J Occup Health. 2017;59:55-62. doi: 10.1539/joh.15-0291-OA.

2. Xue L, Zhang D Wang T, Shou X. Effects of high frequency noise on female rat's multi-organ histology. Noise Health. 2014;16:213-7. doi: 10.4103/1463-1741.137048.

3. Said MA, El-Gohary OA. Effect of noise stress on cardiovascular system in adult male albino rat: implication of stress hormones, endothelial dysfunction and oxidative stress. Gen Physiol Biophys. 2016;35:371-7. doi: 10.4149/ gpb_2016003.

4. Ohrstrom E. Sleep disturbances caused by road traffic noise - Studies in laboratory and field. Noise Health. 2000;2:71-8.

5. Belojević G, Paunović K. Recent advances in research on non-auditory effects of community noise. Srp Arh Celok Lek. 2016;144:94-8.

6. Castle JS, Xing JH, Warner MR, Korsten MA. Environmental noise alters gastric myoelectrical activity: Effect of age. World J Gastroenterol. 2007;13:403-7. doi: 10.3748/wjg.v13. i3.403.

7. Zaghloul MS. Histological, histochemical and biochemical studies of the effect of chronic exposure of noise stress on the kidney of albino rats . J Am Sci. 2011;7:588-98.

8. Pinar T, Atli AK, Alacam H, Alacam H, Karabulut I, Soguksulu I, et al. The effects of noise on oxidative and antioxidative balance in human erythrocytes. Inter J Hematol Oncol. 2011;21:27-37.

9. Lall SB, Singh B, Gulati K, Seth SD. Role of nutrition in toxic injury. Indian J Exp Biol. 1999;37:109-16.

10. Chuang HY, Tsai SY, Chao KY, Lian CY, Yang CY, Ho CK, et al. The influence of milk intake on the lead toxicity to the sensory nervous system in lead workers. Neurotoxicology. 2004;25:941-9.

11. Yu F, Shuai Hao, Bo Yang, Yue Zhao, Jun Yang. Low iron diet increases susceptibility to noise-induced hearing loss in young rats. Nutrients. 2016;8:456. doi: 10.3390/nu8080456.

12. Zicarelli L. Buffalo milk: its properties, dairy yield and mozzarella production. Vet Res Commun. 2004;28:127-35.

13. Ahmad S, Gaucher I, Rousseau F, Beaucher E, piot M, Grongnet JF, et al. Effects of acidification on physicochemical characteristics of buffalo milk: a comparison with cow's milk. Food Chem. 2008;106:11-7.

14. Han X, Lee FL, Zhang L, Guo MR. Chemical composition of water buffalo milk and its low-fat symbiotic yogurt development. Funct Food Health Dis. 2012;2:86-106.

15. Ahmad S, Anjum FM, Huma N, Sameen A, Zahoor T. Composition and physic-chemical characteristics of buffalo milk with particular emphasis of lipids, proteins, minerals, enzymes and vitamins. J Anim Plant Sci. 2013;23:62-74.

16. Al-Asmari AK, Abbasmanthiri R, Al-Elewi AM, Al-Omani S, Al-Asmary S, Al-Asmari SA. Camel milk beneficial effects on treating gentamicin induced alterations in rats. J Toxicol. 2014;2014:917608. doi: 10.1155/2014/917608.

17. Afifi MM. Effect of camel's milk on cisplatin-induced nephrotoxicity in Swiss albino mice. Am J Biochem Biotech. 2010;6:141-7. doi: 10.5455/ajvs.207096.
18. Wybenga DR, Di Giorgio J, Pileggi VJ. Manual and automated methods for urea nitrogen measurement in whole serum. Clin Chem. 1971;17:891-5.

19. Junge W, Wilke B, Halabi A, Klein G. Determination of reference intervals for serum creatinine, creatinine and creatinine clearance with an enzymatic and a modified Jaffé method. Clin Chim Acta. 2004;344:137-48. doi: 10.1016/j. cccn.2004.02.007.

20. Buege JA, Aust SD. Microsomal lipid peroxidation. Methods Enzymol. 1978;52:302-10. doi: 10.1016/s00766879(78)52032-6.

21. Ellman GL. Tissue sulfhydryl groups. Arch Biochem Biophys. 1959;82:70-7. doi: 10.1016/0003-9861(59)90090-6.

22. Oliveira M, Freitas D, Carvalho A, Guimarães L, Pinto A, Águas A. Exposure to industrial wideband noise increases connective tissue in the rat liver. Noise and Health. 2012;14:227-9.

23. Samson J, Sheeladevi R, Ravindran R, Senthilvelan M. Stress response in rat brain after different durations of noise exposure. Neurosci Res. 2007;57:143-7. doi: 10.1016/j. neures.2006.09.019.

24. Manikandan S, Srikumar R, Jeya Parthasarathy N, Sheela Devi R. Protective effect of Acorus calamus LINN on free radical scavengers and lipid peroxidation in discrete regions of brain against noise stress exposed rat. Biol Pharm Bull. 2005;28:2327-30.

25. Helal EG, Eid F,Taha NM. Protective effects of sulpiride treatment on kidney functions of female albino rats exposed to noise stress. EJHM. 2011;44:284-94.

26. Liu L, Shen P, He T, Chang Y, Shi L, Tao S, et al. Noise induced hearing loss impairs spatial learning/memory and hippocampal neurogenesis in mice. Sci Rep. 2016;6:20374. doi: $10.1038 /$ srep20374.

27. Dereköy FS, Dündar Y, Aslan R, Cangal A. Influence of noise exposure on antioxidant system and TEOAEs in rabbits. Eur Arch Otorhinolaryngol.2001;258:518-22.

28. Koc ER, Ersoy A, Ilhan A, Erken HA, Sahin S. Is rosuvastatin protective against on noise-induced oxidative stress in rat serum? Noise Health. 2015;17:11-6. doi: 10.4103/14631741.149565.

29. Ohinata Y, Yamasoba T, Schacht J, Miller JM. Glutathione limits noise-induced hearing loss. Hear Res. 2000;146:28-34.

30. Loukzadeh Z, Hakimi A, Esmailidehaj M, Mehrparvar AH. Effect of ascorbic acid on noise induced hearing loss in rats. Iran J Otorhinolaryngol. 2015;27:267-72.

31. Wang S, Yu Y, Feng Y, Zou F, Zhang X, Huang J, et al. Protective effect of the orientin on noise-induced cognitive impairments in mice. Behav Brain Res. 2016 ;296:290-300. doi: 10.1016/j.bbr. 2015.09.024.

32. Al-Hashem F. Camel's milk protects against aluminum chloride-induced toxicity in the liver and kidney of White albino aats. Am J Biochem. 2009;5:98-109. doi: 10.3844/ ajbbsp.2009.98.108.

33. Afravy M, Angali K, Khodadadi A, Ahmadizadeh M. The protective effect of Buffalo's milk against toluene inducednephrotoxicity in rats. J Nephropathol. 2017;6(3):174-179. doi: $10.15171 /$ jnp.2017.30.

Copyright $\odot 2018$ The Author(s); Published by Nickan Research Institute. This is an open-access article distributed under the terms of the Creative Commons Attribution License (http://creativecommons.org/licenses/by/4.0), which permits unrestricted use, distribution, and reproduction in any medium, provided the original work is properly cited. 